\title{
Gustatory responses during periods of controlled and ad lib cigarette smoking*
}

\author{
ROSE MARIE PANGBORN $\uparrow$ and IDA M. TRABUE \\ University of California, Davis, California 95616
}

\begin{abstract}
Three psychophysical methods, differential sensitivity, perceived intensity, and degree of liking. were used to measure gustatory responses among nonsmokers and among smokers who were placed on 2-week schedules of increased and decreased cigarette consumption. Varying the smoking levels had little influence on the smokers' sensitivity to the tastes of sucrose and sodium chloride. Throughout the experiments. nonsmokers were slightly more sensitive than smokers. Lower intensity ratings were ascribed to both compounds by smokers than by nonsmokers. Degree of liking of the test solutions was unrelated to smoking. A subsequent experiment showed that 45 nonsmokers were slightly; but not significantly, more sensitive than were 45 smokers to the tastes of sucrose. sodium chloride, citric acid, and quinine hydrochloride, with no differences in their sensitivity to the odor of 2-butanone and to the viscosity imparted by carrageenan gum. There was a slight inverse relationship between sensitivity and the number of cigarettes smoked per day. Smokers liked coffee significantly better and drank more cups per day than did nonsmokers. Few changes in body weight were observed. despite the smokers' subjective assessment that their appetites and food intake were inversely related to the number of cigarettes smoked.
\end{abstract}

Heavy smoking impaired gustatory and olfactory acuity according to Sinnot and Rauth (1937). Hall and Blakeslee (1945). Moncrieff (1957). Krut. Perrin, and Bronte-Stewart (1961). Arfmann and Chapanis (1962). Joyner (1963. 1964). Kaplan. Glanville, and Fischer (1964). Matzker (1965). Jackson (1967). and Peterson. Lonergan, and Hardinge (1968). Interestingly. heavy' cigarette smokers showed a strikingly higher proportion of tasters of phenylthiourea than did nonsmokers (Thomas \& Cohen. 1960). However. no differences or only negligible changes in sensitivity between the two groups were reported by Laird (1937). Tilgner and Pikielna (1959). Venstrom and Amoore (1968). Pangborn. Trabue. \& Pikielna (1967). and Martin and Pangborn (1970).

It is difficult to reconcile the conflicting results. but it appears that testing of different Ss using a variety of psychophysical procedures contributed substantially to the controversy. For example, in the articles cited above. the number of $S$ s tested ranged from 1 smoker vs 2 nonsmokers (Moncrieff. 1957) to 646 smokers vs 125 nonsmokers (Thomas \& Cohen, 1960). Test methods included recognition thresholds. difference thresholds. intensity ratings. and preferences. using a variety of gustatory and olfactory stimuli. In none of these investigations has the question been raised as to whether differences in sensitivity between smokers and nonsmokers existed even prior to the smoker's use of tobacco. and the possibility that these initial differences contributed to their becoming smokers.

*Supported in part by the Council for Tobacco Research. I.S.A.

$\div$ Department of l ood Science and Technology. L'niversit! of California. Davis. Callif. 95616
The present study compared three psychophysical methods (sensitivity, perceived intensity, and degree of liking) among smokers on cigarette smoking schedules ranging from total abstinence to twice normal usage, as well as among a comparison group of nonsmokers.

\section{METHOD}

\section{Experimental Subjects}

Ss consisted of male inmates at a nearby minimum-security state prison. Who were screened by the institution. then interviewed. selected. and trained by $E$. Initial selection was made on the basis of dependability. interest and motivation. and freedom from medical or psychiatric impediments. During the first interview. Ss received an oral and written description of the studies and completed a questionnaire concerned with their smoking habits. their food likes and dislikes. their medical histories, and demographic information. Ss under medication which might have influenced their taste or odor perception were evcluded. as were smokers who were apprehensive about reducing or increasing their smoking patterns. A nominal monthly per capita payment was made to the institution. to be received by the inmate upon his release from prison.

Smokers ranged in age from 22 to 45 years $($ mean $=38)$ and had been smoking cigarettes from 10 to 30 years. Nonsmokers. who served as a nonsmoking comparison group. ranged in age from 28 to 63 years ( $m e a n=44$ ), and always had been nonusers of tobacco. During the study. smokers were furnished with the same brand of commercial. nonfiltered cigarette. selected on the basis of their majority preference. The cigarettes were counted and repackaged in polyethylene bags bearing the S's name. and distributed between 8:00 and 9:00 a.m. daily. To asure that this number of eigarettes was smoked. biweekly samples of salis and weekly samples of urine were collected from each $S$ and analyzed for thiocyanate content. a rough inder of cigarette consumption (Densen. Davidow. Bass, \& Jones. 1967: Pikielna \& Pangborn. 1968: Heino. Vilhunen. \& Hirnberg. 1968). Tino smokers "lere eliminated early in the stud? When urinals is indicated that the were not adhering to the prescribed moking instructions. 
INFLUENCE OF SMOKING SCHEDULE ON DIFFERENTIAL SENSITMITY ( $n=64 /$ SUBVECT)

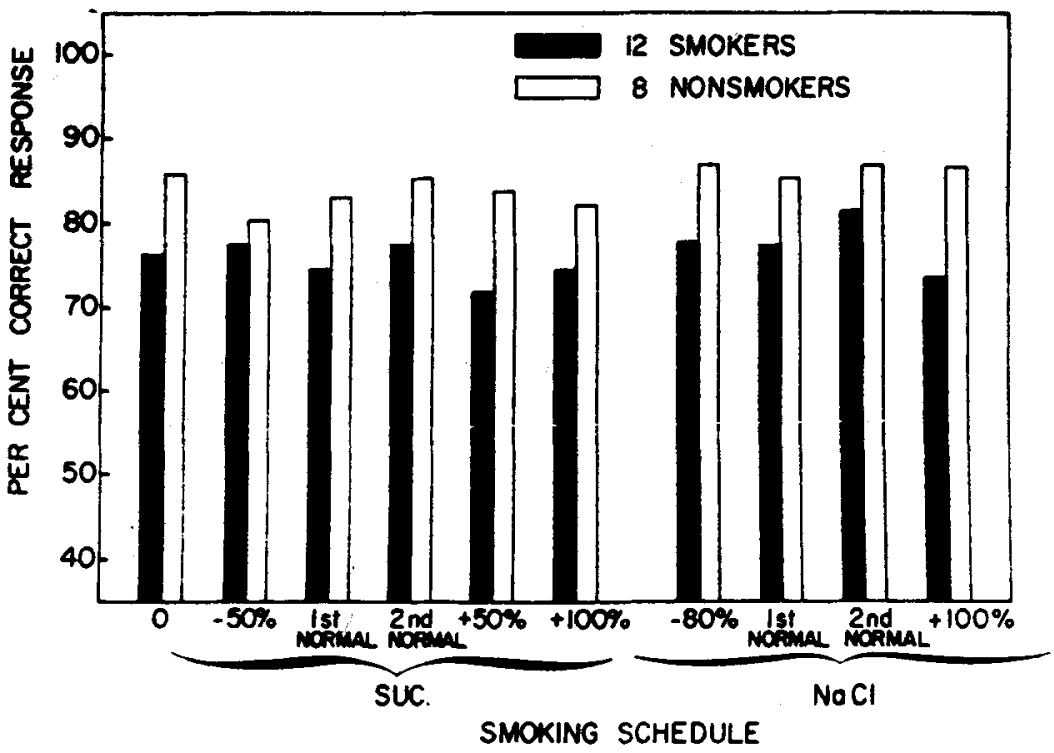

Fig. 1. Differential taste sensitivity of 12 smokers to sucrose (Study I) during six 2-week periods and to sodium chloride (Study II) during four 2-week periods of controlled cigarette smoking. Nonsmokers participated as nonsmoking controls throughout. Percentages are based on individual judgments of 768 (12 Ss $\times 64$ reps) for smokers and 512 (8 Ss $\times 64$ reps) for nonsmokers.

\section{Sensory Procedures}

Stimuli consisted of aqueous solutions of reagent grade sucrose. sodium chloride. citric acid, quinine hydrochloride. 2-butanone (odor of blue cheese), and carrageenan gum (a food thickener). Concentrations were selected in laboratory prescreening to give responses within a desired range. With the one exception noted in Study III. all samples were served at room temperature $\left(21^{\circ} \mathrm{C}\right)$ in $30-\mathrm{ml}$ portions in $60-\mathrm{ml}$ glass bottles. identified with two- or three-digit code numbers on aluminum lids. For all test methods, samples were served in randomized counterbalanced order. Printed instructions accompanied each set of samples. Swallowing was not permitted. but $S$ s could retaste samples within a set. Distilled water at room temperature was provided for oral rinsing. Ss were informed of their results immediately after each test. and provided with cookies as "rewards." Test sessions were scheduled between 8:30 and 10:30 a.m., Tuesday through Friday, from March through December 1967.

Three psychophysical tests were administered in the following sequence: (1) Differential sensitivity-Eight paired samples, one member of each pair consisting of a standard concentration of the compound at a moderately low intensity, with four comparison samples containing less and four containing more than the standard concentration. These concentrations were selected to yield a response between $75 \%$ and $85 r_{c}$ correct across all pairs. Ss circled the code number of the sample with the greater taste intensity within each pair. (2) Intensity rating-Single samples of eight concentrations of the taste compound were presented in randomized order, and the $S$ s rated taste intensity $(0=$ none, and $12=$ intense $)$. (3) Hedonic rating-Single samples of the same eight concentrations as presented for intensity rating were served in randomized order. and the $S$ s rated degree of liking $(1=$ dislike extremely. $5=$ neither like nor dislike. and $9=$ like extremely).

Three independent experiments were conducted in the following sequence: (1) Study I-Twelve from an original group of 16 smokers completed evaluation of sucrose solutions during 2-week periods of normal smoking followed by 50 ' reduction. $50 \%$ increase, $100 \%$ increase, $80 \%-100 \%$ reduction. and normal smoking. Ten nonsmokers were selected as nonsmoking Ss, with 8 completing the experiment. Concentrations employed for the differential sensitivity were $2.0 \%$ sucrose for the standard and
$1.52 \%, 1.64 \%, 1.76 \%, 1.88 \%, 2.12 \%, 2.24 \%, 2.36 \%$ and $2.48 \%$ sucrose for the comparison samples. Concentrations used for the intensity and hedonic evaluations were $0 \%, 0.8 \%, 2.0 \%, 3.2 \%$. $4.4 \%$. $5.6 \%, 6.8 \%$ and $8.0 \%$ sucrose, selected to range from barely perceptible to moderately strong. (2) Study II-Fifteen smokers. 10 of whom had participated in Study I evaluated solutions of sodium chloride during 2-week periods of normal smoking followed by $100^{\circ}$ increase, $80 \%$ to $100^{\circ}$ reduction. and normal smoking. Eight nonsmokers, 7 of whom had participated in Study I. served as nonsmoking Ss. Concentrations of salt used for the differential sensitivity were $0.30^{\circ} \mathrm{C} \mathrm{NaCl}$ for the standard and $0.26 \%, 0.27 \%, 0.28 \%, 0.29 \%, 0.31 \%, 0.32 \%$. $0.33 \%$, and $0.34 \% \mathrm{NaCl}$ for the comparison samples. Concentrations used for the intensity and hedonic evaluations were $0 \%, 0.05 \%, 0.15 \%, 0.30 \%, 0.45 \%, 0.60 \%, 0.75 \%$ and $0.90 \%$ $\mathrm{NaCl}$. (3) Study III-Forty-five smokers and 45 nonsmokers participated. of whom 6 and 3. respectively. had served in Studies I and/or II. Responses to the same concentrations of sucrose and $\mathrm{NaCl}$ as before were measured. as well as to the following compounds and concentrations: $0.008 \%$ citric acid vs $4 \%, 5 \%, 6 \% .7 \% .9 \%, 10 \%, 11 \%$ and $12 \%\left(\times 10^{-3}\right): 0.0025 \%$ quinine vs $5 \%, 10 \%, 15 \%, 20 \%, 30 \%, 35 \%, 40 \%$, and $45 \%$ (x 10-4): $0.0048 \%$ butanone vs $8 \%, 18 \%, 28 \%, 38 \%, 58 \%, 68 \%$. $78 \%$ and $88 \%\left(\times 10^{-4}\right)$; and $0.20 \%$ carrageenan vs $4 \% .8 \% .12 \%$. $16 \%, 24 \%, 28 \%, 32 \%$, and $36 \%\left(\times 10^{-2}\right)$. The $\mathrm{NaCl}$ series was repeated at a solution temperature of $0^{\circ} \mathrm{C}$ to determine whether smokers differed from nonsmokers in their responses to the interaction of taste with temperature. Each series of solutions was administered for 4 consecutive test days. using differential sensitivity. only. All samples were prepared with distilled water on a $v / v$ basis from stock solutions which had been prepared on a w/v basis. Fresh solutions were prepared biweekly.

\section{RESULTS AND DISCUSSION}

\section{Differential Sensitivity}

Results from both Studies I and II are shown in Fig. 1. Responses to sucrose solutions, in the left section of Fig. 1. indicated that nonsmokers were more sensitive than smokers. However. application of Student's t test 
Fig. 2. Differential sensitivity to taste and odor compounds between 45 smokers and 45 nonsmokers (Study III). Percentages are based on 1.440 individual judgments (45 Ss $x 32$ reps).

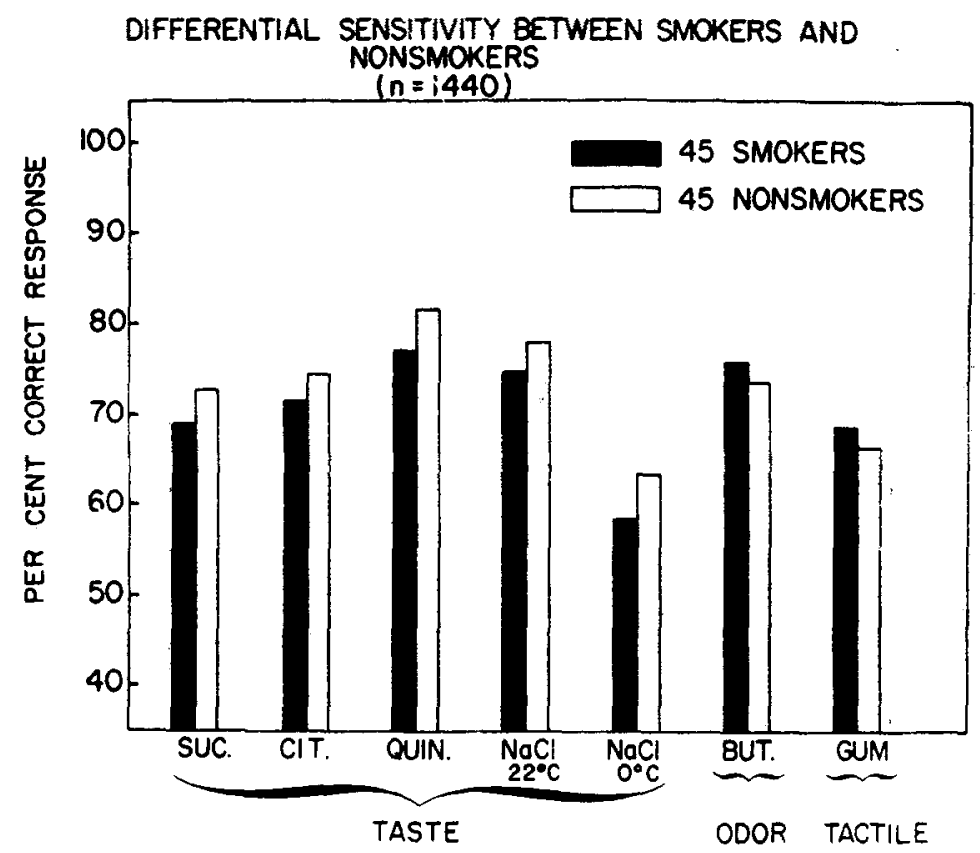

to the total responses of smokers vs nonsmokers was not significant $(t=1.78 . d f=18)$. Analysis of variance for the smokers across the six smoking schedules showed no significant difference attributable to number of cigarettes smoked. There was a large between-smoker variation across the six smoking periods $(p<.001)$. Several Ss improved with practice from the first to the sixth test session. but several showed no change and others showed less acuity.

The right side of Fig. 1 shows that nonsmokers consistently demonstrated a higher number of correct responses to the solutions of $\mathrm{NaCl}$ than did the smokers. Application of Student's $t$ test to the total responses of smokers vs nonsmokers was significant at $\mathrm{p}<.05(\mathrm{t}=$ 2.43. $\mathrm{df}=21$ ). Analysis of variance for data from smokers showed a significant difference $[F(3.42)=3.30$. $\mathrm{p}<.05]$. attributable to the four smoking schedules.

Since results from Studies I and II indicated that the major differences were between smokers and nonsmokers rather than being related to the amount smoked. subsequent tests measured differential sensitivity between 45 nonsmokers and 45 smokers. with the latter using their own brand of tobacco at their normal rates of consumption. Differences in responses between the two groups were not significant. despite the apparent greater sensitivity of the nonsmokers for the taste compounds-sucrose. citric acid. quinine hydrochloride. and sodium chloride (Fig. 2). An unexpected result emerged in the responses to the odor of 2-butanone and to the viscosity of the carrageenan
Fig. 3. Perceived sweetness intensity for sucrose solutions during five periods of controlled cigarette smoking for 12 smokers (Study I). Nonsmokers participated as nonsmoking controls throughout. Each plotted point is the average of 64 individual judgments for nonsmokers ( 8 Ss a 8 reps) and 96 for smokers (12 Ss $>8$ reps).
INFLUENCE OF SMOKING SCHEDULE ON PERCEIVED SWEETNESS

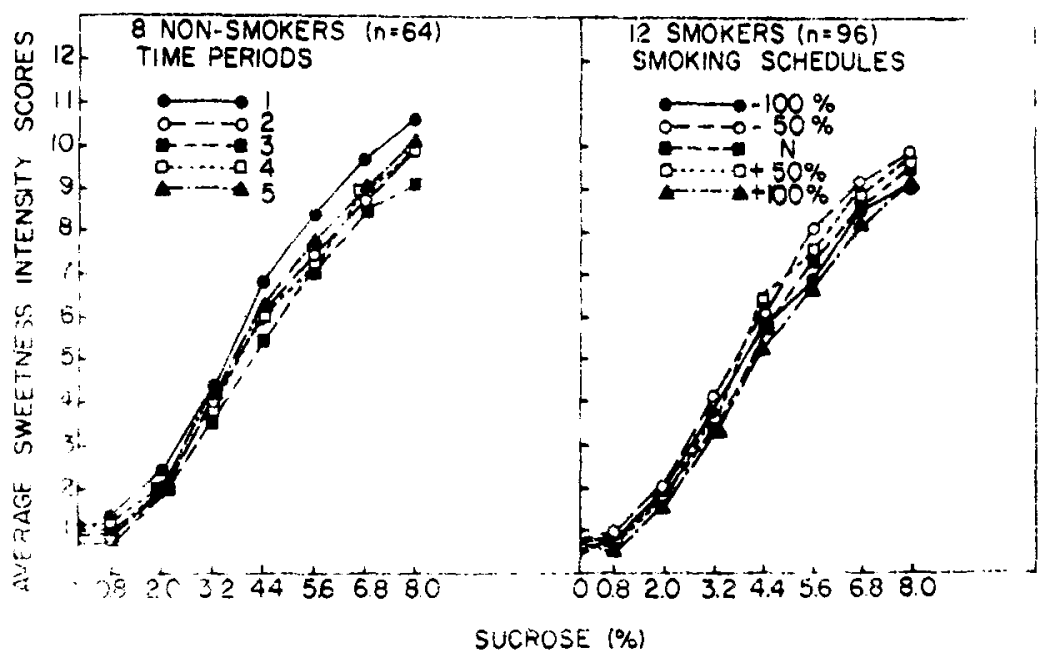




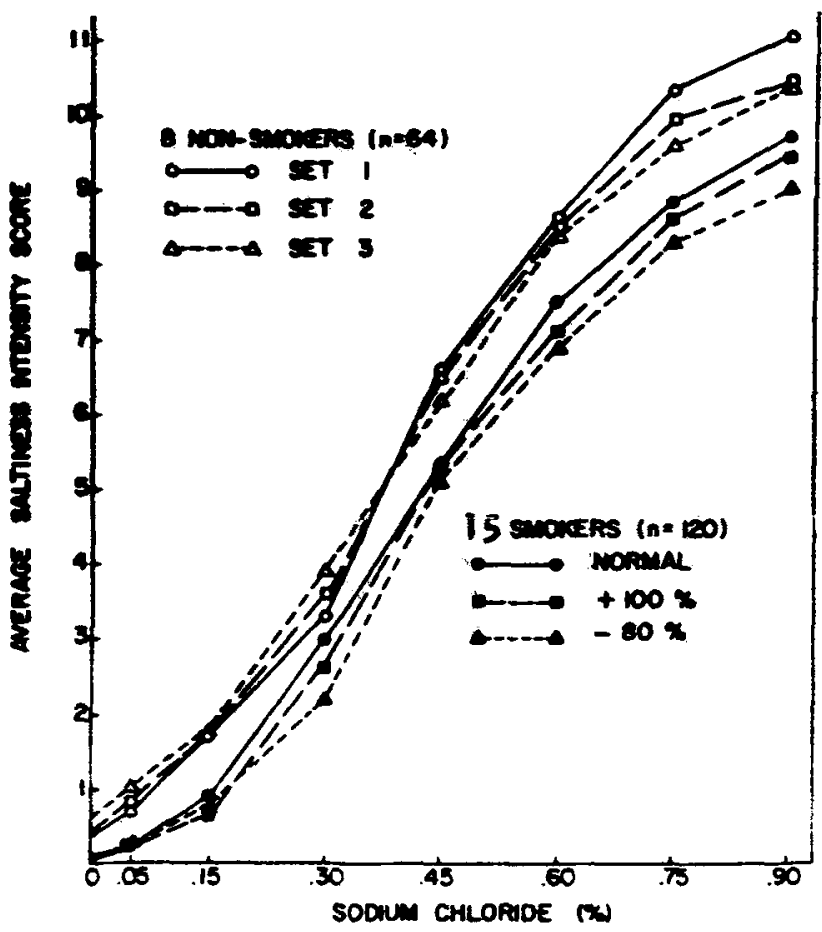

Fig. 4. Perceived saltiness intensity for sodium chloride solutions during three periods of controlled cigarette smoking for 15 smokers (Study II). Nonsmokers participated as nonsmoking controls throughout. Each plotted point is the average of 64 individual judgments for nonsmokers ( 8 Ss $\times 8$ reps) and 120 for smokers (15 Ss $\times 8$ reps).

gum, where smokers were slightly more acute. This indicates a need for additional studies using a wider variety of odor and tactile stimuli. If these latter results were verified in subsequent testing, it would suggest that smoking influences the taste receptors or the tongue surface. but not necessarily the olfactory receptors in the upper nasal cavity or the total oral mechanism utilized in perception of tactile stimuli.

The interaction of the Test Substances by Groups of Ss was not significant. Lowering the temperature of the sodium chloride significantly reduced the taste sensitivity of both groups $(p<.001)$, consistent with previously reported observations (Pangborn. Chrisp. \& Bertolero. 1970).

On the basis of Matzker's (1965) finding of a linear relation between the total number of cigarettes normally smoked and the degree to which the olfactory threshold was raised, correlation coefficients were calculated for the present data, using responses from the "first normal" tests. Correlation coefficients for per diem cigarette consumption vs percent correct response were $r=$ -0.362 for Study I and $r=-0.133$ for Study Il. Corresponding correlation coefficients for Study III were $\mathrm{r}=-0.045$ for the four taste compounds. $\mathrm{r}=$ -0.170 for the odor compound. and $\mathrm{I}=-0.045$ for the gum solution. None of these correlations are significant. vet all are negative. suggesting slightly reduced sensitivity with increased cigarette consumption.

Although every effort was made to monitor the cigarettes smoked during the experiments. it is possible that $S s$ consciously or subconsciously introduced potential sources of error by inhaling differentially, by smoking the cigarette to a different end-point, or by failing to report deviations from the prescribed schedule.

\section{Intensity Ratings}

The taste intensities ascribed to increasing concentrations of sucrose and of sodium chloride are shown in Figs. 3 and 4, respectively. Analysis of variance of these data indicated that perceived taste intensity between smokers and nonsmokers differed significantly $(\mathrm{F}=3.96, \mathrm{df}=1,21, \mathrm{p}<.05)$ for the salt series (Fig. 4), but not for the sugar series (Fig. 3). At all concentration levels. nonsmokers as a group considered the solutions slightly more intense than did the smokers (Fig. 4). Among smokers, both increasing and decreasing the number of cigarettes smoked reduced the apparent saltiness of the solutions $(p<.05)($ Table 1$)$.

\section{Hedonic Ratings}

Little or no difference in hedonic response to sucrose and to sodium chloride was observed as a function of smoking schedule. The overall hedonic means for smokers and nonsmokers, respectively, were 5.3 and 5.2 for sucrose and 4.2 and 4.5 for sodium chloride. This suggests that the smokers liked the sweet stimulus slightly better and the salty stimulus slightly less than did the nonsmokers. Interestingly, the entire group of Ss subdivided itself into three distinct distributions-one with increased degree of liking, a second with decreased degree of liking, and a third where liking increased then decreased with stimulus concentration. Since these trimodal responses were unrelated to smoking, they are reported elsewhere (Pangborn. 1970).

\section{Beverage Consumption and Food Preferences}

Table 2 contains a summary of the likes and dislikes of designated foods and beverages among the 90 Ss participating in Study III. Smokers liked coffee significantly better and drank significantly more of this beverage than did nonsmokers. Beer. but not other

Table 1

Mean Intensity Ratings Assigned to Solutions of Sodium Chloride by 15 Smokers During Controlled Smoking Schedules and by 8 Nonsmokers During Corresponding Time Periods (Study II)

\begin{tabular}{lccc}
\hline & \multicolumn{3}{c}{ Smoking Schedule } \\
\cline { 2 - 4 } & $-80 \%$ & Normal & $+100 \%$ \\
\hline Smokers & 4.1 & 4.4 & 4.2 \\
Xonsmokers & 5.2 & 5.3 & 5.2 \\
\hline
\end{tabular}


Table 2

Mean Values for Cigarette and Coffee Consumption and Food Likes Among 45 Smokers and 45 Nonsmokers (Study III)

\begin{tabular}{|c|c|c|c|}
\hline & Smokers & $\begin{array}{c}\text { Non- } \\
\text { smokers }\end{array}$ & $\begin{array}{c}\text { Student's } \\
t\end{array}$ \\
\hline Years of smoking & 18 & - & \\
\hline Amount smoked (cigs/day) & $26 \dagger$ & - & \\
\hline Coffee consumption (cups/day) & 6.7 & 4.0 & $3.37 * *$ \\
\hline Age (years) & 32.7 & 35.3 & \\
\hline Height (inches) & 70.1 & 69.7 & \\
\hline Weight (pounds) & 163.2 & 169.6 & \\
\hline \multicolumn{4}{|l|}{ Food Likest' } \\
\hline Coffee & 4.4 & 3.8 & $2.78^{* *}$ \\
\hline Tea & 3.6 & 3.6 & \\
\hline Beer & 4.1 & 3.6 & $2.12^{*}$ \\
\hline Sweet wine & 2.6 & 2.9 & \\
\hline Dry wine & 3.1 & 3.0 & \\
\hline Sweets, desserts & 4.1 & 4.3 & \\
\hline Sour foods & 3.8 & 3.8 & \\
\hline Horseradish & 2.7 & 2.9 & \\
\hline Hot chili & 3.5 & 3.6 & \\
\hline Black pepper & 3.7 & 3.4 & \\
\hline
\end{tabular}

trange $=6.40 \mathrm{cigs} / \mathrm{day}$

ffJudged on a 5-point scale: $1=$ dislike very much, $5=$ like very much

***Significant at $p<.05$ and .01 , respectively.

alcoholic beverages, was liked significantly better by smokers. British investigators noted that 84 nonsmokers consumed an average of 4.8 cups of hot beverage (coffee and tea) daily compared to $5.2,7.2,6.8$, and 8.1 cups per day for smokers using $1-4,5-14,15-24$, and $25+$ cigarettes per day, respectively (Bennett, Doll, \& Howell, 1970). It is assumed that smokers like coffee better than do nonsmokers, however the behavioral pattern might be a simple association between smoking a cigarette and drinking a cup of coffee. Bennett, Doll, and Howell also noted a strong positive association between cigarette smoking and sugar intake, much of it in the hot beverages (primarily tea). Whether this phenomenon would be true for American coffee drinkers, many of whom drink unsweetened coffee, remains to be tested.

\section{Weight Changes}

In Study I, smokers complained that they ate more and thereby gained weight when they reduced or ceased smoking. Therefore, in Study II, smokers were weighed every Friday morning prior to their test session to record changes in weight during altered smoking schedules. Each man's weight remained fairly constant independent of the number of cigarettes he smoked. Only two Ss demonstrated a weight gain from their initial weight during the 2-week period when their smoking was greatly curtailed $(197.202 \mathrm{lb}$ and $205.213 \mathrm{lb}$, respectively), but the group average of $175 \mathrm{lb}$ was unaffected by smoking schedule. Possibly 2 weeks is not a long enough time period for weight to change significantly. Glauser, Glauser, Reidenburg, Rusy, and Tallarida (1970) reported that six out of seven Ss gained weight after 1 month's cessation of smoking.

\section{Subjective Feelings \\ During Increased and Reduced Smoking}

Each Friday, smokers described in subjective terms an appraisal of their general well-being during the previous week. They indicated whether there had been increases, decreases, or no change in their appetites, food and liquid intakes, and sleeping patterns as compared to "normal." They reported few, if any, changes when smoking was increased or decreased by $50 \%$ in Study I, but several changes were recorded during the period when they smoked double their normal amount or during the period of no smoking at all (Table 3). For both groups, reduced smoking resulted in an increase in reported appetite and food intake, with the reverse pattern when they smoked double their normal amount. Many Ss reported an increased liquid intake, but since these studies were conducted during the months of June-August, it is difficult to separate fluctuations in ambient temperature from the main effects. Few changes were reported in sleeping pattern, with more adverse comments about general well-being during

Table 3

Smokers' Appraisal of Changes in Appetite, Food and Liquid Intake, Sleeping Patterns, and General Well-Being During Abstinence and When Smoking Double the Normal Amount of Cigarettes

\begin{tabular}{|c|c|c|c|c|c|c|c|c|c|c|}
\hline & \multicolumn{5}{|c|}{$-100 \%$} & \multicolumn{5}{|c|}{$+100 \%$} \\
\hline & Appetite & Liquid & Food & Sleep & General & Appetite & Liquid & Food & Sleep & General \\
\hline \multicolumn{11}{|l|}{ Study I } \\
\hline $\begin{array}{l}\text { Increase } \\
\text { No Change } \\
\text { Decrease }\end{array}$ & $\begin{array}{r}19 \\
8 \\
1\end{array}$ & $\begin{array}{r}18 \\
8 \\
2\end{array}$ & $\begin{array}{r}20 \\
6 \\
2\end{array}$ & $\begin{array}{r}2 \\
22 \\
4\end{array}$ & $\begin{array}{r}0 \\
18 \\
10\end{array}$ & $\begin{array}{r}5 \\
9 \\
14\end{array}$ & $\begin{array}{r}17 \\
9 \\
2\end{array}$ & $\begin{array}{r}5 \\
8 \\
15\end{array}$ & $\begin{array}{r}0 \\
19 \\
9\end{array}$ & $\begin{array}{r}0 \\
14 \\
14\end{array}$ \\
\hline \multirow{2}{*}{$\begin{array}{l}\text { Study II } \\
\text { Increase } \\
\text { No Change } \\
\text { Decrease }\end{array}$} & \multicolumn{5}{|c|}{$-80 \%$} & \multicolumn{5}{|c|}{$+100 \%$} \\
\hline & $\begin{array}{r}16 \\
10 \\
4 \\
\end{array}$ & $\begin{array}{r}7 \\
17 \\
6 \\
\end{array}$ & $\begin{array}{r}15 \\
11 \\
4 \\
\end{array}$ & $\begin{array}{r}4 \\
20 \\
6 \\
\end{array}$ & $\begin{array}{r}1 \\
25 \\
4 \\
\end{array}$ & $\begin{array}{r}1 \\
12 \\
17 \\
\end{array}$ & $\begin{array}{r}18 \\
11 \\
1 \\
\end{array}$ & $\begin{array}{r}1 \\
14 \\
15\end{array}$ & $\begin{array}{r}1 \\
18 \\
11 \\
\end{array}$ & $\begin{array}{r}0 \\
19 \\
11 \\
\end{array}$ \\
\hline
\end{tabular}


increased than during decreased smoking. Among the complaints associated with the increased cigarette usage were: "raw tongue, sore throat, headache, nervous. irritable. and tired." These data suggest that the "intoxication" of excessive smoking is more unpleasant than the "withdrawal" of abstinence, but this remains to be verified in clinical tests.

\section{REFERENCES}

Arfmann. B. L.. \& Chapanis. N. P. The relative sensitivities of taste and smell in smokers and non-smokers. Journal of General Psychology. 1962, 66, 315-320.

Bennett. A. E.. Doll. R., \& Howell, R. W. Sugar consumption and cigarette smoking. The Lancet. 1970. 1. 1011-1014.

Densen. P. M.. Davidow, B., Bass. H. E., \& Jones. E. W. A chemical test for smoking exposure. Archives of Environmental Health. 1967, 14. 865-874.

Glauser. S. C.. Glauser. E. M., Reidenberg, M. M., Rusy, B. F.. \& Tallarida. R. J. Metabolic changes associated with the cessation of cigarette smoking. Archives of Environmental Health. 1970, 20. 377-381.

Hall. A. R.. \& Blakeslee. A. F. Effects of smoking on taste thresholds for phenyl-thio-carbamide (PTC). Proceedings of the National Academy of Science, 1945. 31, 390-396.

Heino. J.. Vilhunen. R., \& Hernberg. S. Urinary thiocyanate concentrations in smokers and non-smokers. Work-Environment-Health. 1968. 5. 12-15.

Jackson. J. A. Heavy smoking and sodium chloride hypogeusia. Journal of Dental Research. 1967, 46. 742-744.

Joyner. R. E. Olfactory acuity in industrial populations. Journal of Occupational Medicine. 1963, 5. 37-42.

Joyner. R. E. Effect of cigarette smoking on olfactory acuity. Archives of Otolaryngology. 1964. 80, 576.579.

Kaplan. A. R.. Glanville. E. V., \& Fischer, R. Taste thresholds for bitterness and cigarette smoking. Nature, 1964. 202. 1366.

Krut. L. H.. Perrin, M. J.. \& Bronte-Stewart, B. Taste perception in smokers and non-smokers. British Medical Journal. 1961, 1. 384-387.
Laird. D. A. The effect of smoking on taste preferences. Medical Record. 1939. 149. 404

Martin, S.. \& Pangborn. R. M. A note on responses to ethyl alcohol before and after smoking. Perception \& Psychophysics. 1970. 8. 169-170.

Matzker. J. Riechen und Lebensalter-riechen und rauchen. Archiv für Ohren-. Nasen- und Kehlkopfheilkunde. 1965. 185. 755-760.

Moncrieff. R. W. Smoking: Its effect on the sense of smell. American Perfumer. 1957, 72, 40-43.

Pangborn. R. M. Individual variation in affective responses to taste stimuli. Psychonomic Science. 1970. 21, 125-126.

Pangborn, R. M.. Trabue, I. M.. \& Pikielna, N. B. Taste, odor, and tactile discrimination before and after smoking. Perception \& Psychophysics. 1967. 2. 529-532.

Pangborn. R. M., Chrisp. R. B.. \& Bertolero, L. L. Gustatory, salivary, and oral thermal responses to solutions of sodium chloride at four temperatures. Perception \& Psychophysics, 1970, 8.69-75.

Peterson, D. I., Lonergan. L. H.. \& Hardinge. M. G. Smoking and taste perception. Archives of Environmental Health, 1968, 16, 219-222.

Pikjelna. N. B.. \& Pangborn. R. M. Effect of cigarette smoking on urinary and salivary thiocyanates. Archives of Environmental Health, 1968, 17, 739-745.

Sinnot. J. J.. \& Rauth. J. E. Effect of smoking on taste thresholds. Journal of General Psychology. 1937. 17, 151-153

Thomas, C. B.. \& Cohen. B. H. Comparison of smokers and nonsmokers. I. A preliminary report on the ability to taste phenylthiourea (P.T.C.). Bulletin. Johns Hopkins Hospital. 1960. 106, 205-215.

Tilgner. D. J., \& Pikielna. N. B. Poziom progu i minimum wrazliwosci zmyslu smaku. Acta Physiologica Polonica. 1959. $10,741.754$.

Venstrom. D., \& Amoore. J. E. Olfactory threshold in relation to age. sex. or smoking. Journal of Food Science. 1968. 33. 264-265.

(Received for publication August 12, 1971: revision received October 3.1972. ) 